18,11

\title{
Объемные и поверхностные эффекты при образовании и разрушении графена на родии
}

\author{
(C) Е.В. Рутьков ${ }^{1}$, Е.Ю. Афанасьева ${ }^{1}$, Н.П. Лавровская ${ }^{2}$, Н.Р. Галль ${ }^{1}$ \\ ${ }^{1}$ Физико-технический институт им. А.Ф. Иофрфе РАН, \\ Санкт-Петербург, Россия \\ ${ }^{2}$ Санкт-Петербургский государственный университет аэрокосмического приборостроения, \\ Санкт-Петербург, Россия \\ E-mail: rutkov@ms.ioffe.ru
}

Поступила в Редакцию 29 апреля 2021 г.

В окончательной редакции 29 апреля 2021 г.

Принята к публикации 7 мая 2021 г.

Изучено образование и разрушение графеновых островков на родии при одновременном учете процессов на поверхности и в объеме металла. Показано, что в равновесии атомы углерода распределены между тремя фазами: графеном, твердым раствором в металле и хемосорбированным углеродом, причем увеличение площади островков требует одновременного увеличения концентрации атомов С и в хемосорбированной, и в растворенной фазах. Определены абсолютные концентрации атомов углерода во всех трех фазах на разных стадиях роста и разрушения графена. Определена энергия активации отрыва атома С от периметра графенового островка на родии, составляющая $E_{\mathrm{det}}=2.7 \mathrm{eV}$. Оценено количество островков графена, которое составляет порядка $10^{10}$ на $\mathrm{cm}^{2}$.

Ключевые слова: графен, фазовый переход, хемосорбированные атомы углерода, родий, твердый раствор.

DOI: 10.21883/FTT.2021.10.51428.101

\section{1. Введение}

Графен обладает уникальными электронными и физико-химическими свойствами, что приковывает к нему внимание многих исследователей [1-13]. Он легко образуется на поверхности металлов как в результате каталитического разложения углеродсодержащих молекул, так и при выделении атомов углерода, растворенных в объеме металла $[7,8]$. Несмотря на научный интерес к графену на металлах, имеется считанное число работ, где такое взаимодействие изучали в сверхвысоковакуумных условиях с помощью современных методов диагностики поверхности. Наиболее часто в качестве подложек используют платиновые металлы, так как они не образуют химических соединений с углеродом - карбидов $[14,15]$, что существенно упрощает анализ физикохимических процессов в системах металл-углерод.

В наших работах [6-8] ранее был детально изучен двумерный фазовый переход в углеродном слое на иридии, приводящий к образованию островков графена и сплошного слоя графена. Иридий единственный металл практически не растворяющий в объеме углерод. Для остальных металлов, например, рения, родия, никеля, платины условия фазового перехода существенно усложняются из-за активного участия в процессе роста островков графена атомов углерода, растворенных в объеме металла [7].

Можно считать, что настоящая работа в некотором смысле завершает цикл работ посвященных фундаментальному исследованию системы родий-углерод[16-21] и посвящена изучению термостойкости графеновых островков и равновесным процессам с их участием.

\section{2. Методика эксперимента}

Эксперименты проводились в сверхвысоковакуумном оже-спектрометре высокого разрешения $(\Delta E / E \leq 0.1 \%)$ с регистрацией Оже-спектров непосредственно при высоких температурах [7,8]. В приборе имелся специальный модуль для применения метода термоэлектронной эмиссии и поверхностной ионизации (ТЭПИ) [9,22]. Образцами служили тонкие родиевые ленты размерами $50 \times 1 \times 0.02 \mathrm{~mm}$ с гранью (111) на поверхности и работой выхода $e_{\varphi}=5.0 \mathrm{eV}$ [8]. Температура ленты измерялась оптическим микропирометром $(1100-1800 \mathrm{~K})$, а при более низких температурах — путем линейной экстраполяции зависимости температуры от тока накала ленты к комнатной температуре. Однородность температуры в средней части ленты $(\sim 40 \mathrm{~mm})$ была не хуже $\pm 5 \mathrm{~K}$. Анализируемый участок ленты в ее середине составлял $\sim 5 \mathrm{~mm}$. Для абсолютной калибровки интенсивности оже-сигнала углерода рядом с рабочей родиевой лентой помещали иридиевую ленту с одним слоем графена с $N_{\mathrm{Cm}}=3.86 \cdot 10^{15} \mathrm{~cm}^{-2}[9]$.

\section{3. Экспериментальные результаты и их обсуждение}

\section{1. Образование графена на родии: одновременный учет роли поверхности и объема}

Графен на родии образовывали стандартным способом - разложением паров бензола $\mathrm{C}_{6} \mathrm{H}_{6}$, напускаемых 
в рабочую камеру до давления $P\left(\mathrm{C}_{6} \mathrm{H}_{6}\right) \approx 1 \cdot 10^{-5}$ Torr, на нагретом образце [16-21]. При этом водород десорбируется и откачивается из камеры, а углерод растворяется в объеме металла и накапливается на поверхности и в объеме образца. На рис. 1 представлена зависимость количества $N_{b}$ углерода, поступающего на $1 \mathrm{~cm}^{2}$ поверхности и растворяющегося в объеме металла (1), и концентрация $N_{0}$ углерода, остающегося на поверхности в фазе графеновых островков (2), от времени науглероживания образца при $T_{\mathrm{C}}=1360 \mathrm{~K}$ и потоке углерода $v_{\mathrm{C}}=2.4 \cdot 10^{14} \mathrm{~cm}^{-2} \cdot \mathrm{s}^{-1}$, поступающего на каждую сторону ленточного образца. Концентрация углерода в фазе хемосорбированного „газа“ находится на уровне $\sim 10^{14} \mathrm{~cm}^{-2}$ и на графике не отражена. Концентрацию $N_{0}$ находили методом зондирования поверхности потоком молекул $\mathrm{CsCl}$, позволяющим определять относительную площадь $s_{0}$ графеновых островков с точностью $\sim 1 \%$ непосредственно в процессе науглероживания, в этом случае $N_{0}=s_{0} \cdot N_{\mathrm{Cm}}$, где $N_{\mathrm{Cm}}=3.86 \cdot 10^{15} \mathrm{~cm}^{-2}-$ концентрация углерода в графене [9].

Из рис. 1 видно, что вначале вплоть до $t=5 \mathrm{~min}$ накопление углерода идет в основном в объеме ленты, при этом $N_{b}=v_{\mathrm{C}} t$. При $t \geq 5 \mathrm{~min}$ происходит фазовый переход первого рода типа конденсации и на поверхности зарождаются и растут островки графена - кривая 2 на рис. 1. При $t \geq 6.5 \mathrm{~min}$ процесс науглероживания заканчивается, на поверхности образовывается сплошной слой графена, на котором диссоциация как молекул бензола, так и молекул $\mathrm{CsCl}$ прекращается. Для времени $5 \mathrm{~min} \leq t \leq 6.5 \mathrm{~min}$ учтено, что на островках графена диссоциация молекул бензола не происходит, что уменьшает эффективный поток атомов углерода: $N_{b}=v_{\mathrm{C}}\left(1-s_{0}(t)\right) t-N_{\mathrm{Cm}} s_{0}(t)$. Отметим, что за счет быстрой диффузии атомов углерода в объеме родия при $T_{\mathrm{C}}=1360 \mathrm{~K}$, зависимость $N_{0}=f(t)$ равновесная, т.е. если прекратить науглероживание, скажем, в момент времени $t=5.5 \mathrm{~min}$, то $s_{0}$ или $N_{0}$ не изменяются на рис. 1 для этого времени $N_{0}=1.6 \cdot 10^{15} \mathrm{~cm}^{-2}$ или $s_{0}=0.4$. Иначе говоря, при равновесии поток $v_{1}$ атомов углерода с островков графена равен потоку $v_{2}$ атомов углерода из хемосорбированной фазы углерода на островки, а поток растворения $v_{3}$ равен потоку углерода $v_{4}$ из объема на поверхность (см. вставку на рис. 1).

Самостоятельный интерес представляет распределение углерода между поверхностью и объемом образца на заключительной стадии науглероживания родия, когда на поверхности появляются графеновые островки время от $t_{\min }=5$ до $t_{\min }=6.5$ на рис. 1. За это время $\Delta t=6.5-5=1.5 \mathrm{~min}$ на образец поступил углерод в количестве $N_{\mathrm{C}}=9 \cdot 10^{15} \mathrm{~cm}^{-2}-$ учитывали уменьшение потока за счет роста островков по площади (см. выше). Отметим, что все расчеты в статье сделаны для толщины ленты равной половине реальной величины, поскольку углерод из бензола поступал симметрично с двух сторон ленточного образца.

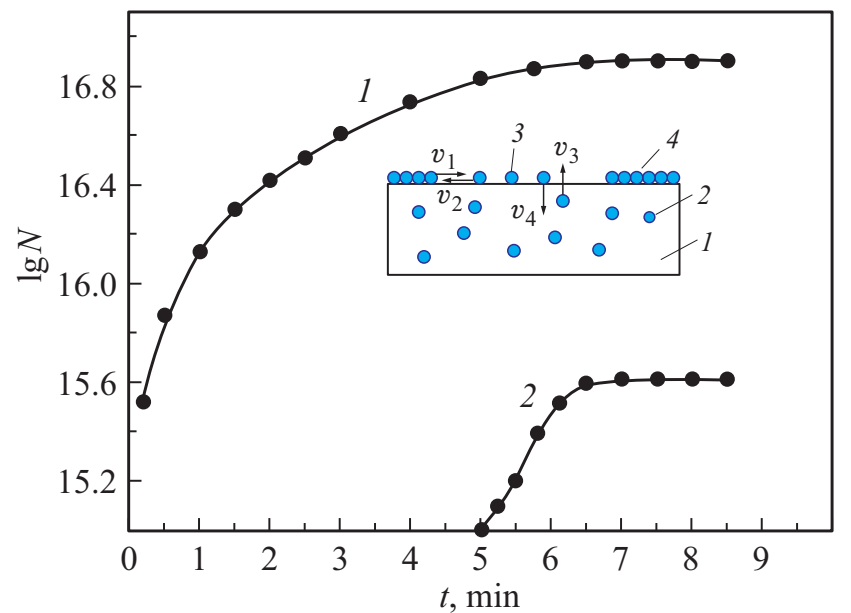

Рис. 1. Зависимости от времени количества углерода $N_{b}$, поступившего на $1 \mathrm{~cm}^{2}$ поверхности родия и растворившегося в объеме металла $(1)$ и концентрации углерода на поверхности родия в фазе графеновых островков $N_{0}(2)$. На вставке упрощенная картина процессов в системе Rh-углерод: 1 металлическая подложка (родий), 2 - атомы углерода, растворенные в его объеме; 3 - атомы углерода на поверхности в хемосорбированной фазе; 4 - атомы С в составе островков графена; $v_{1}$ - поток атомов углерода с краев графеновых островков; $v_{2}$ - поток атомов углерода на края островков; 3 - поток углерода из объема металла на его поверхность; 4 - поток растворения атомов углерода с поверхности в объем металла.

Из поступившего на поверхность углерода за время $\Delta t=1.5 \mathrm{~min}$ на рост графена ушло $N_{0}=N_{\mathrm{Cm}}$ $=3.86 \cdot 10^{15} \mathrm{~cm}^{-2}$, следовательно, за это время в объеме дополнительно растворился углерод в количестве $\Delta N_{b}=v_{\mathrm{C}}\left(1-s_{0}(t)\right) t-N_{\mathrm{Cm}}=5.1 \cdot 10^{15}$ at $\cdot \mathrm{cm}^{-2}$. Это составляет $\sim 7 \%$ от концентрации уже растворенных атомов в нашем образце. Этот опыт показывает, что для роста островков графена по площади при $T=$ const, требуется дополнительное растворение атомов углерода в объеме образца. Это не удивительно, так как в условиях равновесия, когда $v_{1}=v_{2}$ и $v_{3}=v_{4}$ (см. вставку на рис. 1), увеличение одного потока $v_{1}$ за счет роста островков графена по площади (растет периметр островков) должно приводить к изменению потоков $v_{2}, v_{3}$ и $v_{4}$.

В условиях равновесия потоки атомов углерода с поверхности в объем и обратно равны и пропорциональный концентрациями этих атомов в соответствующей фазе. Поэтому, увеличение общего количества углерода в объеме ленты при росте островков графена на 7\%, должно приводить к такому же увеличению количества углерода в фазе хемосорбированного „газа“, что экспериментально зарегистрировать крайне сложно.

Таким образом, с ростом островков по площади растет общий периметр островков, т.е. растет общий поток $v_{1}$ атомов углерода с краев островков. Поэтому для дальнейшего роста островков требуется увеличение кон- 
центрации поверхностного углеродного покрытия, что возможно при дополнительном растворении углерода в объеме ленты, что и наблюдается экспериментально. Отметим, что при росте островков графена по площади $s_{0}$ неизбежен эффект их коалесценции, т. е. в нашем случае изменяется как общий периметр $L$, так и концентрация островков графена $m$ и между ними нет простой связи: $L=f\left(s_{0}, m\right)$.

\section{2. Кинетика и энергетика разрушения графеновых островков на родии}

На рис. 2 показана кинетика разрушения слоя графена на родии для разных температур, при этом следили за изменением относительной площади островков. Начальное состояние - сплошной слой графена $\left(s_{0}=100 \%\right)$, образованный при $T_{\mathrm{C}}=1150 \mathrm{~K}$, при этом объем родия практически свободен от углерода. Видно, что для каждой $T=$ const площадь островков резко уменьшается и затем стабилизируется на некотором равновесном уровне $s_{\text {eq. }}$ Например, для $T=1230 \mathrm{~K}$ (кривая 1 ) $s_{\text {eq }}=35 \%$, а для $T=1280$ (кривая 3 ) $s_{\text {eq }}=7 \%$.

Зависимость $s_{\text {eq }}=f(T)$ наблюдается во многих системах $M e$-графен $[7,8]$ и определяется динамическим равновесием, когда поток атомов углерода с краев островков $v_{1}$ равен потоку атомов $v_{2}$ из „газовой“ хемосорбированной фазы углерода на края островков. Отметим, что минимальная температура начала заметного разрушения графеновых островков $T \geq 1150 \mathrm{~K}$ позволяет оценить энергию связи $E_{\mathrm{det}}$ краевого атома углерода с островком. Действительно известно, что время жизни $\tau$ частицы на поверхности (на краю островка) связано с энергией отрыва $E_{\text {det }}$ соотношением $\tau=\tau_{0} \exp \left(E_{\operatorname{det}} / k T\right)$ [22]. Если положить $\tau_{0} \approx 10^{13} \mathrm{c}$ [22], то для $T=1150 \mathrm{~K}$ и $\tau \approx 1 \mathrm{c}$ получим $E_{\mathrm{det}} \approx 3 \mathrm{eV}$.

Воспользуемся, тем не менее, математическим формализмом развитым нами в работе [23] для описания

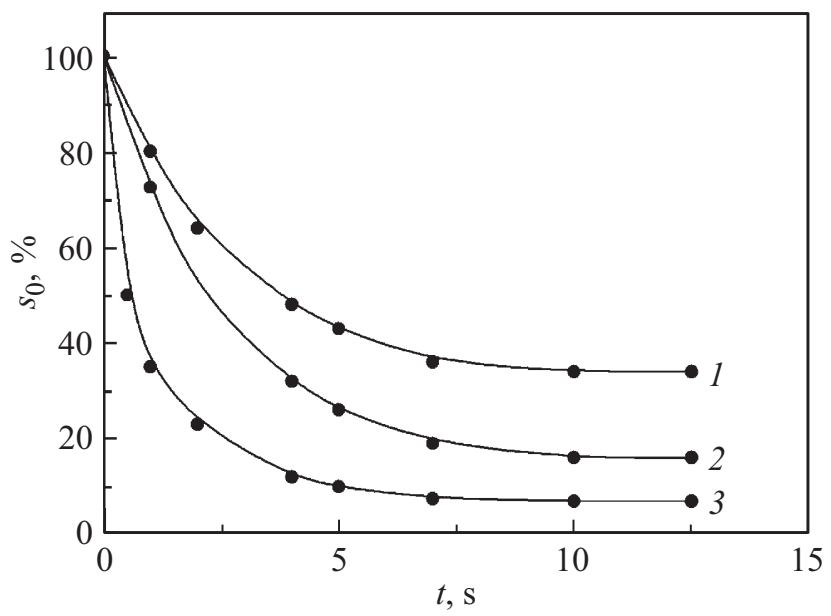

Рис. 2. Зависимость относительной площади $s_{0}$ островков графена на родии от времени при их разрушении (начальное состояние - сплошной слой графена). Температура образца $T, \mathrm{~K}: 1-1205,2-1230,3-1280$.

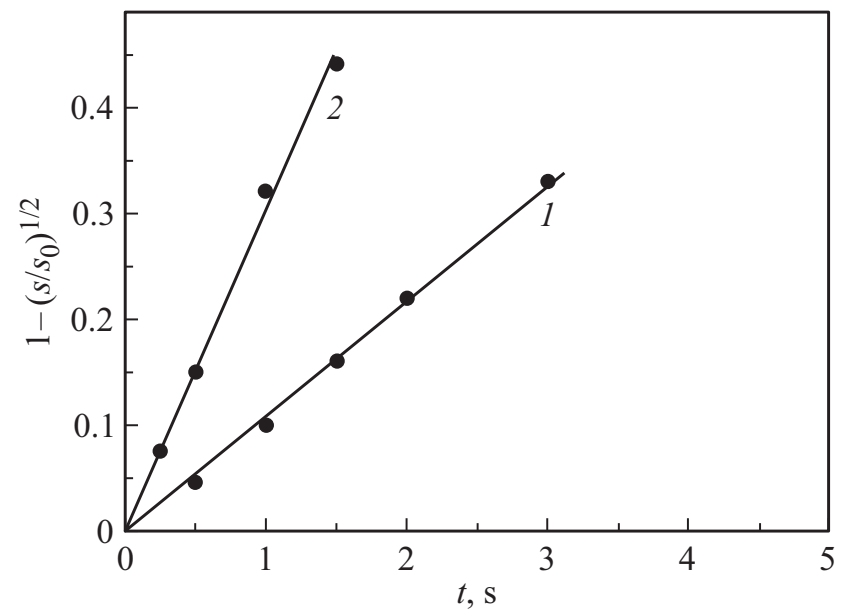

Рис. 3. Зависимость $1-\left(s / s_{0}\right)^{1 / 2}=f(t)-$ обработка начальных участков кривых на рис. 2 для $T=1205 \mathrm{~K}(1)$ и $T=1280 \mathrm{~K}(2)$.

разрушения двумерных бариевых островков на графене. Обработаем только начальные участки кинетики разрушения островков графена в предположении, что обратным потоком $v_{2}$ на островки в этом случае можно пренебречь (рис. 2). Примем упрощенную модель, когда все островки графена это диски одинакового радиуса $R$. В этом случае количество частиц в отдельном островке уменьшается со временем при подъеме температуры согласно уравнению [23]:

$$
-d N / d t=n(t) \mathrm{F} \exp \left(-E_{\mathrm{det}} / k T\right),
$$

где $n$ - число атомов углерода на периметре островка, $\mathrm{F}$ - предэкспоненциальный множитель, $E_{\mathrm{det}}-$ энергия активации отрыва краевого атома углерода от графенового островка. Уравнение (1) легко преобразовать к виду [23]:

$$
1-\left(N / N_{0}\right)^{1 / 2}=-\left[\pi m^{1 / 2} \mathrm{~F} \exp \left(-E_{\operatorname{det}} / k T\right)\right] t / 2 N_{0}^{1 / 2},
$$

где $m$ - концентрация островков на поверхности, $N_{0}=N_{\mathrm{Cm}}$. Величина $N / N_{0}=s / s_{0}$ и находится экспериментально (рис. 2).

На рис. 3 показаны типичные графики экспериментально полученных зависимостей $1-\left(N / N_{0}\right)^{1 / 2}=f(t)$. Видно, что они соответствуют формуле (2).

Из наклона графиков $\ln \left(1-\left(s / s_{0}\right)^{1 / 2}\right)=f(1 / k T)$ при каждой $t=\mathrm{const}$ найдено значение $\mathrm{Edet}=$ $=2.7 \mathrm{eV}$, а из уравнения (2) найдено значение $m^{1 / 2} \mathrm{~F}=1 \cdot 10^{18} \mathrm{~cm}^{-1} \mathrm{~s}^{-1}$. Отметим, что ранее для системы $\operatorname{Ir}(111)-$ графен найдено $E_{\mathrm{det}}=4.5 \mathrm{eV}$, для системы $\operatorname{Re}(1010)$ - графен $E_{\operatorname{det}}=3.0 \mathrm{eV}$, для системы $\mathrm{Ni}(111)$ - графен $E_{\mathrm{det}}=2.5 \mathrm{eV}$ [8]. Полученная в данной работе величина $E_{\mathrm{det}}=2.7 \mathrm{eV}$ хорошо согласуется с температурным интервалом разрушения графеновых островков в указанном ряду подложек. Например, для иридия это $1650-1850 \mathrm{~K}$, для рения $1300-1400 \mathrm{~K}$, а для никеля 950-1050 K [8]. 


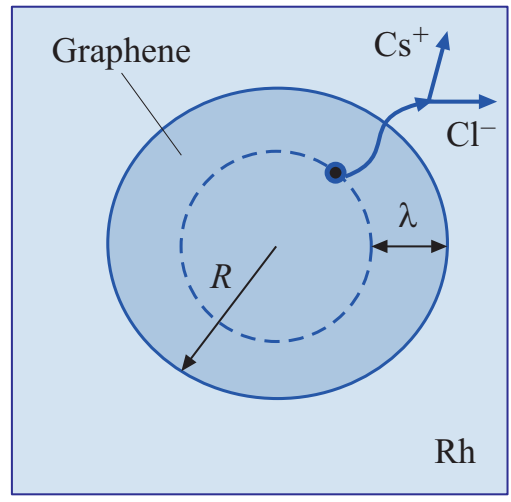

Рис. 4. Упрощенная иллюстрация к методу определения среднего размера графенового островка: $R$ - радиус островка; $\lambda$ - длина миграционного перемещения молекул $\mathrm{CsCl}$ за время их жизни на поверхности графена.

\section{3. Оценка концентрации $\mathrm{m}$ графеновых островков на родии}

Для оценки применяли зондирование поверхности потоком молекул $\mathrm{CsCl}$. Ранее мы показали, что на графене длина миграции $\lambda$ молекул $\mathrm{CsCl}$ за время их жизни на поверхности определяется уравнением $\lambda(\AA)=10 \exp (0.13 / k T)[6,8]$. Например, для $T=1700 \mathrm{~K}$ $\lambda=24 \AA$, т. е. крайне мала и может служить своего рода „линейкой“ для определения размера островков. Действительно, в области высоких температур $1000-1700 \mathrm{~K}$ $s_{0} \neq f(T)$, т.к. радиус островков $R \gg \lambda$. Эксперимент показывает, что при $T \leq 1000 \mathrm{~K}$ измеренная площадь островков графена $s_{0}$ начинает уменьшаться, т.к. длина миграции $\lambda$ становится соизмеримой с размером островка и заметная часть молекул $\mathrm{CsCl}$ промигрирует с островка на металл и там продиссоциирует, что приведет к росту измеренного тока ионов $\mathrm{Cs}^{+}$и, соответственно, приведет к уменьшению измеренной площади островка (рис. 4).

Разумно положить, что экспериментально регистрируется уменьшение площади $s_{0}$ когда $\lambda \leq 0.1 R$, где $R-$ радиус островка. Пусть $s_{0}=50 \%$ или $s_{0}=0.5 \mathrm{~cm}^{-2}$, тогда для случая $T=1000 \mathrm{~K}$ длина миграции молекулы $\mathrm{CsCl}$ по графену будет равна $\lambda=45 \AA$ и значит $R=450 \AA$. В этом случае $s_{0}=m \pi R^{2}$, откуда $m \approx 10^{10} \mathrm{~cm}^{-2}$, что кажется разумным. Например, на $\operatorname{Ir}(111)$ концентрация островков, определенная методом термодесорбционной спектроскопии при взаимодействии молекул кислорода с краевыми атомами углерода равнялась $m \approx 10^{11} \mathrm{~cm}^{-2}$ для $s_{0}=0.4-0.6[24]$.

Выше мы определили величину $m^{1 / 2} \mathrm{~F}=$ $=1 \cdot 10^{18} \mathrm{~cm}^{-1} \mathrm{~s}^{-1}$ для системы $\mathrm{Rh}-$ графен. Если положить $m \approx 10^{10} \mathrm{~cm}^{-2}$, то $\mathrm{F} \approx 10^{13} \mathrm{~s}^{-1}$, что кажется также разумным для кинетических процессов 1-го порядка (адсорбция, десорбция, миграция) для атомов на поверхности твердых тел [22].

\section{4. Равновесные процессы в системе родий-графеновые островки}

На рис. 5 представлены зависимости относительной площади графеновых островков $s_{\mathrm{eq}}$ от температуры образца. Каждая точка на кривых равновесная-поток атомов углерода с краев островков равен потоку углерода на края островков из „газовой“ хемосорбированной фазы (вставка на рис. 1). Параметром кривых являются разные температуры науглероживания образца. В этом случае при переходе от кривой 1 к кривой 2 растет концентрация углерода в объеме металла. В работах [6-9] подробно изучен фазовый переход в углеродном слое на поверхности $\operatorname{Ir}(111)$ и впервые определено равновесное углеродное покрытие $\vartheta_{\text {eq }}=N_{s} / N_{\mathrm{Cm}}=f(T)$ при котором островки графена находятся в равновесии с углеродным „газом“ на поверхности. Иридий практически не растворяет в объеме углерод, поэтому увеличение температуры приводит к уменьшению площади островков графена и увеличению $\vartheta_{\text {eq }}$ углерода на поверхности. При определенной температуре все островки разрушаются и на поверхности находится только хемосорбированный углеродный „газ““ [7]. В системе Rh-графен ситуация похожая, но более сложная поскольку атомы углерода активно растворяются в объеме металла. Подъем температуры уменьшает равновесную площадь островков, при этом атомы углерода пополняют не только поверхностную концентрацию $N_{s}$ углерода, но и растворяются в объеме металла, увеличивая объемную концентрацию углерода $N_{b}$.

Оценим в какой пропорции $N_{b} / N_{s}$ находятся в равновесии углеродный „газ““ на поверхности и углерод в объеме нашего образца с известными геометрическими параметрами: площадь ленты $-1 \mathrm{~cm}^{2}$, а толщина $15 \mu \mathrm{m}$ (половина реальной толщины ленты). Рассмотрим кривую 2 на рис. 5. Для $T_{\mathrm{C}}=1370 \mathrm{~K} N_{b}=3.5 \cdot 10^{16}$ атомов в нашей ленте, а на поверхности только хе-

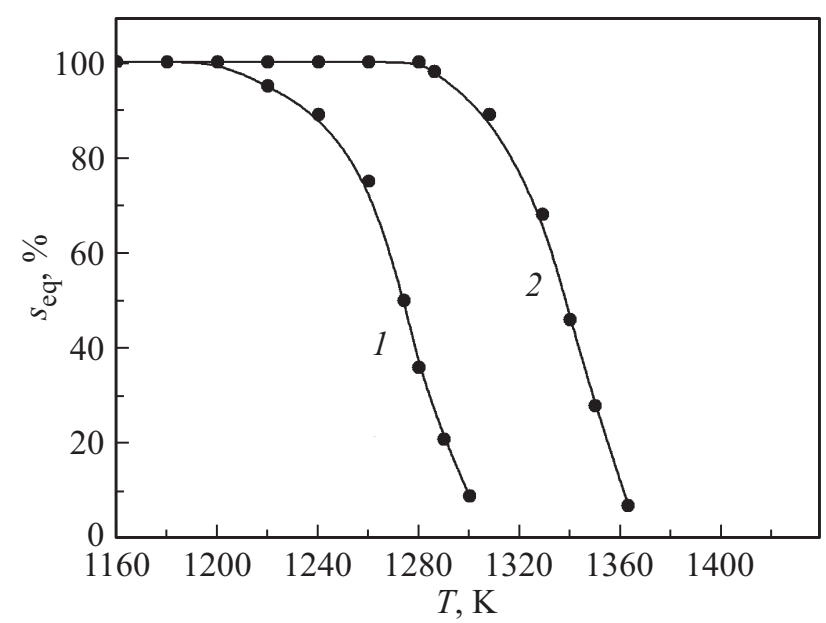

Рис. 5. Зависимость равновесной относительной площади $s_{\mathrm{eq}}$ островков графена на родии от температуры. Концентрация углерода в объеме родия (at.\%): $1-0.05 ; 2-0.069$. 
мосорбированный углеродный „газ“ с концентрацией $N_{s} \approx 5 \cdot 10^{14} \mathrm{~cm}^{-2}$. Таким образом, в условиях равновесия $N_{b} / N_{s} \approx 70$.

При подъеме температуры, например, от $T_{1}=1290 \mathrm{~K}$ до $T_{2}=1340 \mathrm{~K}$ для кривой 2 на рис. 5 относительная равновесная площадь островков графена уменьшается от 100 до 50\%. Дополнительный углерод за счет разрушения графена в количестве $\Delta N=0.5 \cdot N_{\mathrm{Cm}}$ $=1.9 \cdot 10^{15} \mathrm{~cm}^{-2}$ поделится между объемом и поверхностью в соотношении $1: 70$, т.е. поверхностная концентрация увеличится на $\Delta N / 70=2.6 \cdot 10^{13} \mathrm{~cm}^{-2}$, т.е. примерно на 5\%.

Новое равновесное покрытие позволяет получить новое равновесное состояние для островков графена при повышении температуры, но с меньшей относительной площадью и, возможно, с меньшим общим периметром островков. если $m=$ const (рис. 5). В любом случае система „автоподстраивается““ к новым равновесным условиям, где может меняться $s_{0}, L, m$, при этом $L=f(m)$ в условиях коалесценции [25]. Малое увеличение равновесной степени покрытия $\vartheta_{\text {eq }}$ с ростом температуры согласуется с очень слабой зависимостью $\vartheta_{\text {eq }}=f(T)$ определенной нами ранее для системы Rh-графен $[6,8]$.

Рассмотрим сечение двух кривых (1 и 2) для температуры $T=1300 \mathrm{~K}$ на рис. 5 и учтем тот факт, что общее количество углерода в объеме ленты много больше количества углерода на поверхности. Для кривой 1 в равновесии находятся островки графена площадью $s_{1}=10 \%$, а для кривой $2 s_{2}=95 \%$. Казалось бы, если $T=$ const, то равновесное покрытие $\vartheta_{\text {eq }}$ должно сохраняться постоянным независимо от относительной площади островков, как показано в нашей работе для системы Ir-графен [7]. В нашем случае концентрация растворенных атомов углерода при переходе от кривой 1 к кривой 2 увеличилось в 1.5 раза [8] и, следовательно, равновесное покрытие $\vartheta_{\text {eq }}$ также должно вырасти в 1.5 раза при переходе от кривой 1 к кривой 2. Отметим, что измерить равновесное покрытие $\vartheta_{\text {eq }}$ напрямую невозможно, т. к. метод ЭОС не позволяет количественно разделить углеродные фазы на поверхности. На наш взгляд ключевую роль в равновесных процессах играет общий периметр $L$ двумерных графеновых островков. В нашем примере, чем больше $N_{b}$, тем больше $\vartheta_{\text {eq, }}$ тем больший периметр островков $L$ может находиться в „равновесии“ с углеродным „газом“, тем больше равновесная площадь островков графена.

\section{4. Заключение}

Таким образом, определены абсолютные концентрации атомов углерода при его распределении между поверхностью и объемом родия в условиях равновесного роста островков графена. Найдена энергия связи краевого атома углерода с графеновым островком $E_{\mathrm{det}}=2.7 \mathrm{eV}$. Оценена концентрация $m$ островков графена на родии, $m \approx 10^{10} \mathrm{~cm}^{-2}$. Показано, что в условиях равновесия для
$T=$ const увеличение островков по площади требует дополнительного увеличения концентрации углерода как на поверхности, так и растворенного в объеме металла, поскольку в равновесии концентрация углерода в фазе хемосорбированного „газа“ зависит от общего суммарного периметра $L$ островков, который в свою очередь зависит от площади $s_{0}$ островков $\left(L \propto\left(s_{0}\right)^{1 / 2}\right)$ и от их концентрации $m(L \propto m)$.

\section{Конфликт интересов}

Авторы заявляют, что у них нет конфликта интересов.

\section{Список литературы}

[1] К.С. Новоселов. УФН 81, 12, 1299 (2011).

[2] А.К. Гейм. УФН 81, 12, 1284 (2011).

[3] W. Zhao, F. Duan. Tribology Lett. 68, 32 (2020).

[4] S. Xu, Lipeng Zhang, B. Wang, R.S. Ruoff. Cell Rep. Phys. Sci. 2, 3, 100372 (2021).

[5] X. Zhang, S. Wang. RSC Adv. 9, 32712 (2019).

[6] E.V. Rut'kov, N.R. Gall. Physics and Applications of Graphene-Experiments / Ed. S. Mikhailov. In Tech, Rijeka, Croatia (2011). C. 209.

[7] N.R. Gall, E.V. Rut'kov, A.Ya. Tontegode. Int. J. Mod. Phys. 11, 1865 (1997).

[8] Н.Р. Галль, Е.В. Рутьков. Физика поверхности твердых тел. Графен и графит на поверхности твердых тел. Изд-во Политех. ун-та, СПб (2013). 160 с.

[9] A.Ya. Tontegode. Prog. Surf. Sci. 38, 201 (1991).

[10] J. Wintterlin, M.-L. Bosquet. Surf. Sci. 603, 1841 (2009).

[11] S.M. Kozlov, F. Vifies, A. Görling. J. Phys. Chem. C 116, 13, 7360 (2012).

[12] J. Wouter, F. Craes, C. Busse. Phys. Rev. B 91, 115419 (2015). DOI:https://doi.org/10.1103/PhysRevB.91.115419

[13] E.N. Voloshina, Yu.S. Dedkov. Phys. Chem. Chem. Phys. 14, 13502 (2012).

[14] Е. Фромм, Е. Гебхардт. Газы и углерод в металлах. Металлургия, М. (1980). 711 с.

[15] Г.В. Самсонов. Тугоплавкие соединения. Металлургия, М. (1963). $398 \mathrm{c.}$

[16] Е.В. Рутьков, Е.Ю. Афанасьева, Н.Р. Галль. ФТП 54, 6, 552 (2020).

[17] Е.В. Рутьков, Н.П. Лавровская, Е.С. Шешеня, Н.Р. Галль. ФТП 51, 4, 517 (2017).

[18] Е.В. Рутьков, Н.Р. Галль. Письма ЖЭТФ 100, 10, 708 (2014).

[19] Е.В. Рутьков, А.В. Кузмичев, Н.Р. Галль. Письма ЖЭТФ 93, 3, 166 (2011).

[20] Е.В. Рутьков, Н.Р. Галль. ФТП 52, 9, 111 (2018).

[21] Е.В. Рутьков, А.В. Кузмичев, Н.Р. Галль.ФТТ 53, 5, 1026 (2011).

[22] Э.Я. Зандберг, Н.И. Ионов. Поверхностная ионизация. Наука, М. (1969). 432 с.

[23] Э.Я. Зандберг, Е.В. Рутьков, А.Я. Тонтегоде, Н.Д. Потехина. ФТТ 9, 1665 (1977).

[24] В.Н. Агеев, С.М. Соловьев, А.Я. Тонтегоде. ФТТ 23, 2280 (1981).

[25] Е.В. Рутьков, Н.Р. Галль. ФТТ 62, 3, 508 (2020).

Редактор К.В. Емщев 